\title{
Mitologia se Ensina na Escola? Reflexões a partir do Curso de Licenciatura Intercultural Indígena da UFSC
}

\author{
Antonella Tassinari ${ }^{1}$ \\ ${ }^{1}$ Universidade Federal de Santa Catarina, Florianópolis, SC, Brasil
}

\section{Resumo}

Cursos de Licenciatura Intercultural Indígena têm propiciado momentos instigantes de reflexão sobre a pertinência das categorias analíticas utilizadas pela Antropologia para a compreensão das categorias indígenas e para sua utilização nas escolas das aldeias (TASSINARI et al., 2019). O artigo parte da experiência de lecionar a disciplina Mitologia Indígena, ao longo do ano de 2016, para os acadêmicos guarani, kaingang e xokleng-laklãnõ do Curso de Licenciatura da UFSC. Os trabalhos desenvolvidos na disciplina permitiram ampliar o campo semântico dos termos mito e mitologia para abarcar termos como: narrativa, conselho, dança, fofoca, cantigas, receitas, restrições alimentares, marcas corporais, oração, maldição, adivinhação, técnicas de caça. Ao descrever o processo de elaboração do programa da disciplina e sua desconstrução ao longo dos dois semestres de curso, pretende-se contribuir para uma reflexão sobre o diálogo intercultural na sala de aula e sua potência para a desconstrução de categorias de análise antropológicas.

Palavras-chave: Mitologia. Escola Indígena. Interculturalidade. Ensino Superior.

\section{Can we teach Mythology at School? Reflections from an Intercultural Training for Indigenous Teachers at UFSC}

\begin{abstract}
Undergraduates Intercultural Training for Indigenous Teachers have provided instigating opportunities of reflection on the relevance of the analytical categories used by Anthropology for the understanding of indigenous categories and for their use in indigenous schools (Autor et all 2019). The article comes from the experience of teaching the courses of Indigenous Mythology, throughout 2016, for Guarani, Kaingang and Xokleng-Laklãnõ academics from the UFSC Undergraduate Intercultural Training. The final works of the course allowed to expand the semantic field of the terms myth and mythology to include terms such as: narrative, advice, dance, gossip, songs, recipes, dietary restrictions, body marks, prayer, curse, divination, hunting techniques. By describing the process of preparing the course's program and its deconstruction over the two semesters of the course, it is intended to contribute to a reflection on intercultural dialogue in the classroom and its potential for deconstructing anthropological analytical categories.
\end{abstract}

Keywords: Mythology. Indigenous School. Interculturality. Higher Education. 


\section{Introdução}

$\mathrm{E}$ ste artigo se constrói a partir da experiência das disciplinas Mitologia I e Mitologia II lecionadas no ano de 2016 junto a 45 acadêmicos/as guarani, kaingang e xokleng que compõem a segunda turma do Curso Licenciatura Intercultural Indígena do Sul da Mata Atlântica da UFSC (LII $)^{1}$. Parte também da experiência prévia da disciplina Mitologia Kaingang, oferecida em 2011 para 40 acadêmicos/as kaingang da primeira turma daquele curso. O Curso LII foi instituído na UFSC em 2011 na esteira dos cursos fomentados pelos editais PROLIND/MEC, objetivando a formação de professores indígenas em nível superior, com uma proposta intercultural, com o intuito de suprir as necessidades das escolas indígenas.

A primeira turma tinha 120 alunos (40 de cada povo) e previa a habilitação de professores em Educação Infantil e Séries Iniciais do Ensino Fundamental. Em 2015, 78 estudantes se formaram e defenderam trabalhos de conclusão de curso. Uma nova turma teve início em 2016, dessa vez com 45 alunos ( 15 de cada povo) e um novo currículo visando à habilitação para lecionar no Ensino Médio e Séries Finais do Ensino Fundamental. Essa turma, com 37 formandos, colou grau em 2020, em meio à pandemia de COVID-19.

Ambas as turmas foram aprovadas na UFSC como turmas "piloto", embora o curso seja regularizado junto ao Ministério da Educação (MEC). Para a institucionalização e a oferta contínua do curso junto à UFSC e às Secretarias de Educação, algumas iniciativas têm sido feitas pelas sucessivas coordenações, buscando parcerias com vários departamentos e centros de ensino da Universidade, a contratação de professores efetivos, especialmente professores de línguas indígenas, a construção de um alojamento estudantil e a oferta de transporte das aldeias à universidade nos períodos de aulas. Em 2020, um novo Projeto Político Pedagógico (PPP) do curso foi aprovado, com entradas sucessivas após a formatura de cada turma, e previsão de realização de processo seletivo no início de 2022.

O currículo é desenhado segundo a Pedagogia da Alternância, que vem sendo utilizada para a formação de professores em Educação no Campo e Educação Indígena e abarca períodos intensivos de aulas (são três períodos de 15 dias por semestre) e períodos de atividades dirigidas nas próprias comunidades. Busca-se oferecer uma formação crítica, baseada na interculturalidade e visando a uma descolonização dos saberes acadêmicos, princípios que, por certo, encontram muitos desafios para sua efetivação.

O artigo é uma versão ampliada de comunicação oral apresentada na XII Reunião de Antropologia do Mercosul, em 2018 em Posadas, Argentina, no GT 71: Mitologia, Diversidade Religiosa e Produção Etnográfica entre os Autóctones na América ou outras Partes do Mundo, coordenado por Robert Crépeau, Aldo Litaiff e Rogério Rosa. 
Um desses desafios é a divisão por "disciplinas" que, em termos curriculares/ pedagógicos, busca-se superar com a proposta de projetos transdisciplinares que relacionem as atividades do conjunto de disciplinas ofertadas em um semestre. Mas pelo próprio desenho disciplinar do currículo universitário e do sistema de gerenciamento de matrículas, o projeto transdisciplinar precisou ser desenvolvido no âmbito de uma disciplina intitulada Projetos de Pesquisa em Ação, ofertadas em todos os semestres, com o propósito de promover uma reflexão transversal sobre as disciplinas, uma aproximação com as aldeias e as escolas indígenas dos/as acadêmicos/as e o desenvolvimento paulatino de projetos de pesquisa com vistas à realização de Trabalhos de Conclusão de Curso. As disciplinas Mitologia I e Mitologia II, ofertadas no início do curso ( $1^{\mathrm{a}}$ e $2^{\mathrm{a}}$ fases), objetivam também propiciar uma reflexão sobre essa diferença entre conhecimentos acadêmicos distanciados da prática e fragmentados em áreas do conhecimento (as "matérias" escolares) e a capacidade dos mitos em integrar o conhecimento à prática, e abarcar a totalidade da experiência humana de modo holístico.

Em outro trabalho (TASSINARI et al., 2019), focado na experiência da disciplina Infância Indígena ofertada para a primeira turma da LII/UFSC, discutimos a potência e a fertilidade de utilizar as discussões de sala de aula de um curso de Licenciatura Intercultural Indígena para provocar um "deslocamento" em nossos modelos de análise:

Sugerimos a importância de refletirmos sobre a adequação dos nossos modelos para pensar a infância, de modo análogo ao que fez Strathern (2006) a respeito do gênero. Não se trata de discutir se gênero ou infância são categorias universais, mas de pensar nas metáforas que têm sido usadas por outros povos para categorizar as diferenças entre crianças e adultos. Nas nossas aulas, percebemos que os acadêmicos nos indicavam a necessidade de um "deslocamento", nos termos da autora, dos limites de nossa linguagem. Esse "deslocamento" indicava que as metáforas utilizadas por eles para definir crianças e adultos não se colocam como oposições ou atributos da pessoa ou de fases da sua vida. Fomos percebendo que infância poderia referir às posições que uma pessoa ou seu espírito ocupa num campo que envolve relações de parentesco e cosmológicas. [...] Ao mesmo tempo, apontamos para a riqueza de conhecimentos que são trazidos para uma sala de aula de Licenciatura Intercultural Indígena e a efervescência que produzem quando permitimos que provoquem um "deslocamento" de nossos modelos e conceitos. (TASSINARI et al., 2019, p. 412)

Neste artigo pretende-se explorar esse argumento demonstrando como o processo de ensino-aprendizagem, baseado numa constante tentativa de escuta, acabou gerando a desconstrução dos próprios termos que norteavam a disciplina (mito e mitologia), indicando os limites da nossa linguagem (STRATHERN, 2006). O resultado foi uma completa transformação da proposta original do curso, a partir de uma reflexão sobre possíveis traduções do termo "mitologia" para suas línguas, que acabou motivando a alteração do próprio nome da disciplina, na proposta curricular apresentada em 2020, de Mitologia Indígena I e II para Memória Viva I e II. É essa experiência que pretendo apresentar neste artigo. 


\section{Por que Ensinar Mitologia em um Curso de Formação de Professores Indígenas?}

A Licenciatura Intercultural Indígena do Sul da Mata Atlântica, voltada para indígenas que vivem na parte meridional do Bioma Mata Atlântica (Guarani, Kaingang e Laklãnõ-Xokleng), tem como eixo-norteador "Territórios e Conhecimentos no Bioma Mata Atlântica" e habilitação para os anos finais do Ensino Fundamental e para o Ensino Médio. O Projeto Político Pedagógico (PPP, 2015) prevê duas terminalidades, definidas a partir do $5^{\circ}$ semestre: Licenciatura do Conhecimento Ambiental e Licenciatura em Artes e Linguagens. As disciplinas Mitologia I e II, ofertadas no primeiro ano do curso, visam propiciar uma reflexão sobre regimes próprios de conhecimento que são importantes para as duas terminalidades. Entendo que as questões tratadas na disciplina são fundamentais para a própria garantia de processos de aprendizagem interculturais, conforme explicitado no PPP do curso:

Por fim, garantir os processos singulares de ensino aprendizagem neste curso de formação de indígenas significa atentar às visões de mundo, à mitologia, às concepções próprias de tempo, às práticas sócio culturais específicas, aos conhecimentos sobre a natureza, aos valores de fortalecimento da identidade do grupo, à organização social do povo, aos saberes da comunidade advindos da tradição e da memória coletiva. (PPP, 2015, p. 30)

Além disso, considero que um tratamento adequado da mitologia, que a compreenda como memória viva de um povo, é condição para o próprio diálogo intercultural, na medida em que abre espaço para um campo de conhecimentos indígenas que não podem ser dirigidos para campos disciplinares acadêmicos, já que os excede: o campo de suas epistemologias e ontologias.

Com essa perspectiva, comecei a elaborar o programa das disciplinas, procurando ultrapassar o teor teórico expresso nas suas ementas: "Estudo dos mitos, símbolos, ritos e noção de sagrado em cultura s indígenas" (Mitologia I) e "Estudos sobre as qualidades do conhecimento mítico, suas características e formas de transmissão, observando as possibilidades de sua utilização nos processos de ensino e aprendizagem" (Mitologia II) (PPP, 2015).

A experiência de lecionar Mitologia Kaingang para uma classe de 40 estudantes da primeira turma já havia demonstrado a potencialidade e os desafios da disciplina. Antes de tudo, porque as turmas guarani e laklãnõ-xokleng puderam escolher os professores da disciplina, enquanto a turma kaingang não me conhecia e duvidava que eu pudesse lhes ensinar sua mitologia. Foi um primeiro esforço mostrar-lhes que o objetivo da disciplina era refletir sobre as origens dos termos mito e mitologia e como poderiam ser traduzidos para a língua kaingang e pensarmos na relação dessas formas de conhecimentos "mitológicos" com a experiência escolar.

No entanto, na afobação de iniciar o curso, descuidei da valiosa orientação de Paulo Freire (1970) e iniciei a disciplina falando dos gregos, ao invés de partir das experiências dos/as estudantes. O plano foi bem-intencionado: contar-lhes o mito do nascimento dos gêmeos Artêmis e Apolo, filhos de Zeus e Leto, associados à lua e ao sol, que imaginei iria remeter-lhes ao mito de origem das metades kamé e kairu (CRÉPEAU, 1997). Dito e 
feito! Como bons ouvintes, a turma se interessou pela narrativa e logo teceu comparações com os irmãos míticos Kamé e Kairu, sol e lua, trazendo vários elementos da mitologia Kaingang. Seguiu-se daí toda a explicação sobre a origem grega do termo mito e sua importância como fonte legítima de conhecimento para aquele povo até aproximadamente o século VIII a.C. Segundo Jean-Pierre Vernant (2002), com o advento da polis, de uma nova ordem política e difusão de uma nova forma de escrita, entre os séculos VIII e IV a.C., ocorreu uma ruptura entre razão (logos) e mito (mithos), quando a história escrita se firmou como fonte legítima de conhecimento em detrimento das narrativas orais. Procurava lhes mostrar as origens de um movimento de deslegitimação da mitologia e das tradições orais, que procuraríamos criticar ao longo do curso, a partir de abordagens antropológicas ou da história oral.

Falei grego demais para o início da disciplina. A turma logo reclamou, com razão, que tínhamos que falar sobre os Kaingang! Para promover uma reflexão sobre a interculturalidade, trouxe outro mito grego, de Eco e Narciso, comparando com as dificuldades que eu, como professora, e eles/as como estudantes, estávamos sentindo de parar de olhar para nós mesmos e nos engajarmos num diálogo intercultural. O resultado dessa atividade foi bastante positivo e ampliou nossa capacidade de conversação. Trazer um mito para pensar numa situação da sala de aula também ajudou a trazer legitimidade para as narrativas míticas.

O passo seguinte foi pensar no "campo semântico" do termo "mito" que, para a tradição eurodescendente poderia abarcar "narrativa, história, canto, conto, poesia, lenda, fábula, etc.". E o desafio que lhes apresentei foi: "Qual a possibilidade de traduzir esse campo semântico do mito nos termos kaingang?". A proposta estava inspirada no que explica Vansina $(2010$, p. 144) a respeito das tradições orais africanas: "Toda literatura oral tem sua própria divisão em gêneros literários" e confesso que era mais ou menos o que esperava que os/as estudantes kaingang fossem discutir. Para minha surpresa, após refletirem em grupo e na própria língua, o resultado da atividade trouxe um campo semântico alargado e com critérios próprios, abarcando, além de narrativas de diferentes tipos (fofocas, histórias para crianças, narrativas históricas), também restrições alimentares, danças e teatro. Os termos apresentados foram os seguintes:

Quadro 1 - Resultado de atividade em sala de aula, turma Kaingang, em 2011

\begin{tabular}{|l|l|}
\hline \multicolumn{1}{|c|}{ Termo em kaingang } & \multicolumn{1}{c|}{ Descrição em português } \\
\hline Ó & $\begin{array}{l}\text { Histórias com ensinamentos, contadas de noite, } \\
\text { quando as crianças estão deitadas }\end{array}$ \\
\hline Venhuí - wewi & Fofoca ou notícia \\
\hline Kouén & Coisas que não se pode comer \\
\hline Kombê & Fatos históricos \\
\hline & Danças \\
\hline & Teatro \\
\hline & Segredos de Caça \\
\hline
\end{tabular}

Fonte: Elaborado pela autora deste artigo 
Nesse primeiro momento, em sala de aula, nem todos os termos em kaingang foram lembrados. Mas já ficou evidente a insuficiência da definição habitual de "mito" no campo das narrativas de um povo, especialmente aquelas que tratam dos primórdios dos tempos ou das situações originárias. Destaco que seus critérios para classificar os gêneros não se relacionam somente às suas formas e conteúdos (VANSINA, 2010), mas incluem um momento específico em que as histórias "ó" são contadas e uma posição particular da plateia (deitada), ou relação das narrativas com ações, como segredos relacionados às técnicas de caça, ou os tabus e proibições alimentares. Interessante incluírem também as fofocas nesse campo semântico, pois, conforme nos ensinou Cláudia Fonseca a respeito de camadas populares em Porto Alegre/RS, são importantes recursos para a transmissão de valores e princípios morais, assim como demarcam as fronteiras de um grupo social (FONSECA, 2000).

Acredito que uma experiência importante daquela turma e que pode tê-los auxiliado a trazer práticas corporais para o campo semântico da mitologia (como danças, teatro, segredos de caça), foi a realização de um projeto de extensão coordenado por Beleni Saléte Grando, que ofertava jogos e práticas corporais de diversas tradições nos intervalos das aulas da LII, como tentativa de trazer alguma atenção à corporalidade no cotidiano do curso, em geral com muitas horas de sala de aula. Assim, foram realizadas rodas de capoeira, práticas de yoga e práticas inspiradas em várias tradições indígenas (GRANDO, 2010).

Para desenvolver as definições construídas em sala de aula, foram propostas atividades para o Tempo-Comunidade, com o intuito de cada estudante aprofundar essa reflexão junto à sua comunidade: "Pesquisar as formas Kaingang de classificar a mitologia/ sabedoria (como nos exemplos do trabalho feito em sala), definir essas várias categorias, escrever uma história de cada tipo, conversar com a comunidade sobre a importância de trabalhar essas histórias na escola (considerando as diferenças das várias fases: $1^{\mathrm{a}} \mathrm{a}$ $4^{\mathrm{a}}, 5^{\mathrm{a}}$ a $8^{\mathrm{a}}$, Ensino Médio)".

Os resultados foram muito ricos, mas desenvolvidos por cada estudante ou grupo de estudantes de uma mesma comunidade. Infelizmente, não foi possível retomar o trabalho coletivo para complementar o quadro acima. Por meio dessas atividades, soube que as escolas kaingang têm uma disciplina específica, Cultura Kaingang, e vários trabalhos apresentados no retorno do Tempo Comunidade se referiam a experiências em curso nessas disciplinas. Uma delas, considerada positiva, é a experiência das "Noites Culturais", promovidas para valorizar as formas tradicionais de transmissão de conhecimentos, garantindo que as histórias "o" possam ser devidamente contadas nas escolas, de noite, com as crianças deitadas. Outra experiência, considerada desastrosa, foi a realização dos rituais Kiki (CRÉPEAU, 1997) como performances de demonstração realizadas na escola. Trata-se de um ritual fúnebre que, nesse caso, foi realizado sem haver uma morte que o justificasse. "Começou a morrer gente toda semana", explicou o aluno da LII e professor em sua aldeia, justificando que alguns assuntos não poderiam ser incluídos na escola.

Esse último exemplo aborda uma questão importante que procurei tratar na disciplina, a respeito da utilização da mitologia indígena na sala de aula, de modo a refletir e definir o que deve ou não deve ser assunto escolar. A própria proposta de pensar a escola indígena como "fronteira" (TASSINARI, 2001) previa analisar não somente as possibilidades de 
trânsito e diálogo entre conhecimentos indígenas e escolares, mas também situações de interdição, quando os indígenas preferem manter certos aspectos de seu cotidiano distanciados na escola.

Viertler (1979) desenvolve uma importante crítica sobre a adaptação de mitos indígenas na literatura infantil brasileira, fazendo algumas sugestões sobre o adequado tratamento de histórias indígenas para que crianças não-indígenas possam aprender de modo respeitoso sobre outras formas de viver a infância. Embora não seja o caso que tratamos aqui, já que falamos do uso da mitologia nas escolas indígenas, algumas reflexões da autora devem ser levadas em conta, especialmente no que tange à complexidade dos mitos e sua adequação para ser assunto das séries iniciais ou mesmo para ser objeto de treino de escrita. Pereira (2021), ao citar sobre a educação de seu povo Piratapuia do Rio Negro, fala das narrativas kirtí, que define como narrativas curtas que trazem fragmentos de mitos maiores para serem compreensíveis para as crianças. Por meio dos kirtí, as crianças são apresentadas a diferentes espécies animais em breves associações com narrativas míticas mais amplas, que só irão conhecer mais tarde e a partir da sua própria iniciativa e curiosidade. Esse exemplo demonstra a importância de partir de categorias nativas, de classificações próprias dos gêneros narrativos, para se refletir sobre a pertinência de seu uso na sala de aula.

E o que falam os parâmetros norteadores das escolas indígenas a respeito da utilização da mitologia nas escolas? Lembremos que os Referenciais Curriculares para Escolas Indígenas (BRASIL, 1997), menciona o termo "mito" 50 vezes ao longo de suas 331 páginas, sugerindo o uso de mitos para o tratamento de temas transversais e também como assuntos para abordar conteúdos de várias matérias: línguas, matemática, história, geografia, ciências, artes e educação física.

Já o Guia do Formador, parte do kit Parâmetros em Ação, material publicado pelo MEC em 2002 para subsidiar a discussão dos Referenciais Escolares para Escolas Indígenas, propõe, no módulo 10 "Elaborando o currículo na escola", a atividade 6 "Nem tudo se ensina na escola", que tem como objetivo:

Promover uma discussão sobre os limites da escola indígena, evidenciando a necessidade de ela estar integrada ao cotidiano da vida na aldeia e a importância da comunidade na tomada de decisões relativas ao projeto político-pedagógico que se quer construir para a escola indígena. (BRASIL, 2002, p. 211)

A atividade proposta no Guia do Formador é a discussão do vídeo “Do outro lado do céu" da série Índios no Brasil, produzida pela TV Escola, que trata justamente de rituais dos Yanomami de Roraima, dos Pankararu de Pernambuco e dos Maxacali de Minas Gerais $^{2}$. A proposta é que cada escola indígena possa refletir se o que foi apresentado no vídeo deve ou não deve ser objeto de estudo escolar.

Ou seja, a reflexão sobre a pertinência de trabalhar questões relativas ao mito, ao rito e ao xamanismo, merece ser feita em cada caso e era esse um dos objetivos que a disciplina Mitologia Kaingang e, posteriormente, Mitologia Indígena, procuravam atingir. O que ficou evidente, como veremos, é que essa reflexão só pode ser desenvolvida a partir de um "deslocamento" das metáforas que temos usado para pensar mito e mitologia.

2 Disponível em: https://youtu.be/oy0oxtCAm-U. 


\section{3 “Nós não temos mitos": reconceitualizando a Mitologia}

A partir da experiência anteriormente descrita e dos documentos norteadores e bases teóricas mencionadas, preparei o plano de ensino para a disciplina Mitologia I visando atender aos seguintes objetivos: 1) partir das definições próprias de "mitologia" para cada povo (FREIRE, 1970); 2) apresentar a origem desse termo no pensamento euro descendente, considerando a origem grega, as poesias épicas e a subsequente separação entre mythos e logos (VERNANT, 2002); 3) refletir criticamente sobre as consequências desta separação na produção do campo científico: afirmação da história escrita sobre as narrativas orais, afirmação de métodos científicos sobre outras formas de conhecimento, produção de "verdades" no campo científico (LOPES DA SILVA, 1995); 4) apresentar brevemente algumas possibilidades de analisar a mitologia: mito como narrativa, estrutura, performance; e 5) conhecer os trabalhos acadêmicos sobre a mitologia de cada povo. Para a disciplina Mitologia II, planejei as seguintes metas: 6) discutir sobre as relações entre mito, rito, história, território, considerando as experiências específicas de cada povo; 7) discutir as possibilidades e desafios da utilização da mitologia na escola indígena: implicações da escrita dos mitos (conforme análise crítica de Viertler (1979); 8) comparar as formas de transmissão do conhecimento mítico e formas de transmissão do conhecimento escolar; e 9) desenvolver um projeto de aprofundamento pessoal sobre algum tema da mitologia do próprio povo.

Os planos de ensino eram ambiciosos e muito mais amplos do que poderia ser realizado em dois semestres. Mas a ideia principal era, partindo de um diálogo com a turma sobre as noções próprias de mito/mitologia, redimensionar o programa para aprofundar alguns dos tópicos e, no segundo semestre, estimular os/as estudantes a desenvolverem uma pesquisa sobre algum tema relacionado à mitologia de seu povo e pensar na possibilidade/adequação de trabalhar esse tema na escola.

Lembrando que o ritmo das disciplinas da LII/UFSC segue os seguintes períodos de alternância, a cada semestre: 15 dias de uma primeira etapa de Tempo-Universidade $\left(1^{\circ}\right.$ TU), quando são apresentados os objetivos da disciplina, são discutidos conceitos iniciais e são propostas atividades para serem desenvolvidas junto à comunidade da aldeia do/a estudante durante a primeira etapa de Tempo-Comunidade ( $\left.1^{\circ} \mathrm{TC}\right)$. Na segunda etapa de 15 dias de Tempo-Universidade ( $2^{\circ} \mathrm{TU}$ ), são aprofundados os conteúdos da disciplina à luz das experiências e resultados das atividades desenvolvidas na etapa anterior e são propostas novas atividades para a segunda etapa do Tempo-Comunidade $\left(2^{\circ} \mathrm{TC}\right)$, quando os projetos individuais ou em grupo devem ser concluídos e trazidos para apresentação e discussão na terceira e última etapa de Tempo-Universidade ( $\left.3^{\circ} \mathrm{TU}\right)$. Assim, os planos de ensino também buscam se beneficiar desses períodos alternados entre Universidade e comunidades dos/as estudantes.

Estava me sentindo muito confiante de iniciar o curso com as definições de "mito" e "mitologia" de cada povo, buscando trazer para a sala de aula o "saber de experiência feito" de que fala Paulo Freire (1992). Para minha surpresa, quando propus uma discussão sobre o tema, os/as estudantes se apressaram em dizer "nós não temos mitos", "nossas histórias são verdadeiras"! Achei que seria uma ótima oportunidade de trazer a história 
da Grécia para falar de onde vem a associação entre "mito" e "conhecimento errôneo e falso", por meio de exposição de slides.

Também procurei mostrar que há áreas de ciência, como a própria Antropologia, que levam os mitos a sério. Lemos conjuntamente e discutimos o texto de Lopes da Silva (1992), que apresenta uma introdução ao tema dos mitos e cosmologias indígenas, com claras definições dos termos e bons exemplos sobre as diferenças de ênfases em cosmologias de povos de língua Jê, Tupi e Tukano, que levaram os/as estudantes a fazerem interessantes comparações com suas experiências. Segundo a autora, trabalhamos com as seguintes definições:

Os mitos são, por tudo o que vimos, um lugar para a reflexão. Através de signos concretos, e de histórias e personagens maravilhosos, os mitos falam de complexos problemas filosóficos com que os grupos humanos, por sua própria condição no mundo, devem se defrontar. (LOPES DA SILVA, 1995, p. 327)

Cosmologias são teorias do mundo. Da ordem do mundo, do movimento no mundo, no espaço e no tempo, no qual a humanidade é apenas um dos muitos personagens em cena. Definem o lugar que ela ocupa no cenário total e expressam concepções que revelam a interdependência permanente e a reciprocidade constante nas trocas de energias e forças vitais, de conhecimentos, habilidades e capacidades que dão aos personagens a fonte de sua renovação, perpetuação e criatividade. Na vivência cotidiana, essas concepções orientam, dão sentido permitem interpretar acontecimentos e ponderar decisões. São, de modo sintético, expressas com clareza exemplar através da linguagem altamente simbólica da dramaturgia dos rituais. (LOPES DA SILVA, 1992, p. 76)

Durante as discussões em sala, a recusa em tratar suas narrativas como "mitos" continuava muito presente. Um pouco frustrada com essa insistência, lembrei do diálogo que Paulo Freire descreve ter tido com sua esposa Elza, no início de sua carreira, após sair de uma reunião em que ofereceu uma palestra a um grupo de operários e, pelos comentários destes ao final da palestra, achou que não fora compreendido:

- Pensei que havia sido tão claro - disse eu. - Parece que não me entenderam. - Não terá sido você, Paulo, quem não os entendeu? - Perguntou Elza, e continuou: - creio que entenderam o fundamental de sua fala. O discurso do operário foi claro sobre isto. Eles entenderam você, mas precisavam de que você os entendesse. Essa é a questão. (FREIRE, 1992, p. 39)

É impressionante como essa lição de Elza Freire precisa ser atualizada a todo momento na sala de aula. No caso da minha turma, parece que haviam entendido muito bem toda a discussão que lhes apresentei. Faltava que eu entendesse que nada disso mudava o fato de que o termo "mito" é veiculado cotidianamente em contraste com o termo "verdade". E que definir seus conhecimentos ancestrais como "mitos" lhes era ofensivo, pois os associava a "não verdades".

Optamos por seguir com o termo "mitologia" como uma alternativa provisória e fizemos um exercício de criar uma "definição intercultural" desse termo que nos serviria de tema gerador para as próximas atividades. Chamamos de "definição intercultural" pois resultou de uma tentativa de diálogo entre os conhecimentos acadêmicos que eu lhes tinha apresentado (LOPES DA SILVA, 1992; 1995) e os conhecimentos guarani, kaingang e laklãno-xokleng. Assim, após discussão em sala de aula em 10 de junho de 
2016, a seguinte definição intercultural de "mitologia" foi construída: São narrativas que uma população acredita. Um sistema que orienta a vida. Um sistema que estabelece uma ordem/organização.

A partir dessa definição, propus as seguintes atividades para o $1^{\circ}$ TC: “1) Pesquise quais as palavras na sua língua podem ser usadas para traduzir "mitologia", considerando que o campo semântico desse termo inclui narrativas, histórias, contos, poesias, músicas; 2) Como essas palavras podem ser descritas em português? Explique seu campo semântico e a sua forma de enunciação: quem pode contar, em que contexto, com que estilo, etc.". Observo que, mesmo com a experiência prévia da turma kaingang, continuei dando ênfase às narrativas, em detrimento de outros gêneros que haviam me apresentado, como danças, segredos de caça, etc. Vejamos que o resultado das atividades novamente desconstruiu essa ideia, ampliando o campo semântico para abarcar não só formas de pensar e narrar, mas também modos de ser, conhecer e fazer.

Com os resultados dessas atividades realizadas no $1^{\circ} \mathrm{TC}$, os/as estudantes voltaram para o $2^{\circ} \mathrm{TU}$, quando trabalhamos em três grupos, relacionados a cada um dos povos, na busca de elaborarem um quadro que abarcasse todas as contribuições que trouxeram de suas comunidades. Os quadros a seguir apresentam os resultados desse trabalho em grupo. É interessante que as turmas kaingang e laklãnõ-xokleng, antes de apresentar os termos em suas línguas, fizeram questão de reforçar o aspecto verídico dessas narrativas ou práticas, inclusive apresentando os especialistas que sabem fazê-las, no caso da turma kaingang.

TURMA GUARANI

Quadro 2 - Resultado de atividade em sala de aula, turma Guarani, em 2016

\begin{tabular}{|l|l|}
\hline \multicolumn{1}{|c|}{ Termo em Guarani } & \multicolumn{1}{c|}{ Tradução e descrição } \\
\hline AYU MARAEY & $\begin{array}{l}\text { Ditos sagrados, fala religiosa, palavras dos mais velhos } \\
\text { depois da reza }\end{array}$ \\
\hline NHEMONGUETA & Conselho \\
\hline NHANDEREKO YMANGUARE & Modo de ser antigo. O antes e o agora. \\
\hline ANHETENGUA & A verdade dita. Palavras verdadeiras. Música. \\
\hline ARANDU REKO & Conhecimento sobre a memória \\
\hline KUA MBOÉ & Prática. Conhecer e ensinar. \\
\hline NHANDEREKO YPYRÃ & Narrativa sobre a história do começO. \\
\hline
\end{tabular}

Fonte: Elaborado pela autora deste artigo 


\section{TURMA KAINGANG:}

Narrativas que falam do que existe. É verdade.

Especialistas: Kuya, parteira, peg.

Quadro 3 - Resultado de atividade em sala de aula, turma Kaingang, em 2016

\begin{tabular}{|l|l|}
\hline \multicolumn{1}{|c|}{ Termo em Kaingang } & \multicolumn{1}{c|}{ Tradução e descrição } \\
\hline Ó & Narrativas que ensinam as crianças, tem uma moral \\
\hline VÊMÊ & Fofoca, situações do cotidiano \\
\hline KOVÃNH & Restrições alimentares \\
\hline VÊNHGRÉN & Dança. Apresentada em velórios. \\
\hline TYGTYNH & $\begin{array}{l}\text { Cantigas. Canto ritual antes de ir à guerra. Casamento. Tentear. } \\
\text { Velório. }\end{array}$ \\
\hline KÃME & $\begin{array}{l}\text { História que os antigos sabem. Uma receita de uma comida } \\
\text { típica. A história da dança da chuva. }\end{array}$ \\
\hline JÃNGÃN & Cada situação tem um sentido para cada marca. \\
\hline
\end{tabular}

Fonte: Elaborado pela autora deste artigo

\section{TURMA LAKLÃNÕ-XOKLENG}

\section{São verdades}

Quadro 4 - Resultado de atividade em sala de aula, turma Laklãnõ-Xokleng, em 2016

\begin{tabular}{|l|l|}
\hline Termo em Laklãnõ-Xokleng & \multicolumn{1}{c|}{ Tradução e descrição } \\
\hline DÉN KABEL & Narrativas \\
\hline VANHVE & Espírito que tem histórias. Exemplo: passarinho \\
\hline JÃNKÁGNÃG & $\begin{array}{l}\text { Visão do cosmos espiritual que a pessoa tem quando está } \\
\text { prestes a morrer }\end{array}$ \\
\hline KÓ PLÁG & Ritual através do fogo. Visão. \\
\hline AGGLAN & Canto - música - poesia \\
\hline VÃBEL & Conto de histórias. Conselho. \\
\hline HÁTAN & Oração que gera uma previsão \\
\hline AGDJAN & Maldição. Jogar praga. \\
\hline GLÉN & Cantigas de abençoar crianças, viúva, casamento. \\
\hline HÓN & Marcas corporais \\
\hline
\end{tabular}

Fonte: Elaborado pela autora deste artigo

Observamos, com esse exercício, uma ampliação do campo semântico da mitologia, para abarcar uma diversidade de estilos de narrativas ou práticas definidas segundo critérios também muito distintos. Temos descrições mais próximas de nossas definições clássicas de "mitos" como o nhandereko ypyrã que os/as estudantes guarani traduziram por "narrativas sobre a história do começo", ou o vãbel traduzidos pelos/as acadêmicos/ as laklãnõ-xokleng como "conto de histórias, conselho", ou dén kabel como "narrativas".

Mas, em geral, as descrições falam sobre outros critérios para classificar os termos, que podem ser a intenção das evocações (as bênçãos glén, ou as maldições agdjan laklãnõxokleng, por exemplo), a consequência das evocações (as orações laklãnõ-xokleng hatan que geram uma previsão), a quem as narrativas são dirigidas (como as histórias ó voltadas 
para as crianças kaingang), o momento de enunciação (o próprio ó, contado de noite antes de dormir, os ayu maraey, ditos sagrados guarani, "palavras dos mais velhos depois da reza", ou os tygtynh kaingang, cantos realizados antes de momentos específicos como guerra, caça, casamento ou funeral) ou mesmo quem pode enuncia-las (como o kãme kaingang que abarca conhecimentos das pessoas mais velhas, incluindo narrativas e receitas culinárias). As definições abarcam expressões musicais (anhetengua guarani, agglan, canto-música-poesia lãklãno-xokleng), gráficas (hon, marcar corporais laklãnõxokleng), culinárias (tanto as restrições alimentares kovãnh kaingang, quanto as receitas dos antigos que são um tipo de kãme). Vemos também, nos dois grupos Jê, referências à organização social, seja nas marcas corporais hon laklãnõ-xokkeng, seja na definção de jãngãn kaingang, que faz referência às marcas das metades clãnicas.

Importa destacar, nessas definições, que a maioria dos termos se define numa relação com a prática ou alguma experiência sensível, quando não são os próprios termos dotados de alguma qualidade espiritual. Por exemplo, kua mboé é justamente definido pela turma guarani como "prática, conhecer e ensinar", já a turma laklãnõ-xokleng descreveu vanhve como "espírito que tem histórias", além de dois tipos diferentes de "visões": jãnkágnãg ("visão do cosmos espiritual que a pessoa tem quando está prestes a morrer") e o kó plág, (visão obtida de modo ritual através do fogo). O termo vênhgrén kaingang remete às danças realizadas em funerais.

Ou seja, por mais que tentemos encapsular a mitologia no campo do pensamento, da reflexão, das teorias de mundo, que acabam tendo morada nas mentes individuais, as metáforas que os/as acadêmicos/as indígenas trouxeram transbordam essas referências e colocam a mitologia em prática, em ação, na interação social e na experiência sensorial. Isso ficará mais evidente adiante, em relação aos temas trabalhados por cada estudante na disciplina Mitologia II.

Ainda sobre esses resultados, podemos fazer algumas considerações pensando nas especificidades de cada povo e algumas aproximações entre as turmas kaingang e laklãnõ-xokleng, podem ser apontadas. Ambos são povos de língua Jê que tiveram contato com a educação escolar desde os anos 1940, por meio de iniciativas do SPI. Essa longa experiência de escolarização contrasta com os Guarani de Santa Catarina, que vieram recusando sistematicamente a educação escolar em suas aldeias até a década de 1990, quando as primeiras escolas indígenas foram instaladas nas aldeias do Estado (OLIVEIRA, 2004).

Essas diferentes experiências de escolarização têm levado a um perfil diferenciado do alunado da LII, conforme observou Melo (2014) para a primeira turma, que também se repetiu na segunda turma. Enquanto os/as acadêmicos/as guarani são os/as primeiros/ as da família a frequentarem escolas, os/as acadêmicos/as laklãnõ-xokleng e kaingang têm pais ou avós escolarizados. Alguns, inclusive, são filhos de professores/as indígenas. Isso faz com que as rotinas e discursos escolares lhes sejam, de certo modo, conhecidos e já naturalizados. Os Kaingang, inclusive, já têm uma disciplina escolar definida, Cultura Kaingang, para tratar do que vem sendo trabalhado como conhecimentos tradicionais. Assim, de certo modo, a "fronteira" (TASSINARI, 2001) entre conhecimentos tradicionais e escolares já foi sedimentada no processo escolar. Já a turma guarani expressou uma 
maior abertura para discutir temas da mitologia na escola e uma menor necessidade de afirmação da legitimidade ou veracidade de suas definições desse campo semântico.

Cada quadro poderia levar a um instigante aprofundamento sobre a cosmologia e mitologia de cada povo, mas, no que tange àquela disciplina, estávamos interessados em pensar nas diferenças de cada gênero narrativo ou performático e na adequação ou inadequação de seu tratamento nas escolas indígenas. Assim, para o $2^{\circ} \mathrm{TC}$, a proposta de atividades foi a seguinte: "Como o tema da mitologia tem sido trabalhado na sua sala de aula? Ou na sua escola? Ou na escola de sua aldeia? Verifique se alguma das definições de 'mitologia' apresentadas na primeira atividade avaliativa estão sendo trabalhadas na sua escola (por você mesmo ou por colegas). Acrescente esse item ao relatório a ser apresentado para a disciplina de Projetos de Pesquisa e Ação I". No caso, a proposta foi realizar um trabalho conjunto com a disciplina articuladora de projetos transdisciplinares que estava focalizando na história da escola de cada comunidade 3 .

Outros temas trabalhados no $2^{\circ} \mathrm{TU}$, na forma de breves aulas expositivas, com ajuda de apresentação de slides, foram: abordagens científicas sobre mitos: Psicologia, Antropologia, Sociologia; mitos como inconsciente, arquétipo, narrativa, estrutura, moral: a partir das contribuições de Freud, Jung, Frazer, Lévi-Strauss, Durkheim, Eliade. Propus uma breve atividade avaliativa a ser entregue no final da etapa, para consolidar o que foi aprendido, partir de duas perguntas: "No pensamento ocidental, o mito é sempre tratado como falso? Escreva o que você aprendeu sobre as análises acadêmicas sobre a mitologia". Foi interessante notar que os autores mais citados em suas respostas foram James Frazer e Mircea Eliade, dois estudiosos de mitologias comparadas que, cada um a seu tempo, buscaram semelhanças entre mitologias de diferentes povos e procuraram demonstrar a lógica própria dos mitos. No caso de Frazer, valorizaram sua análise dos princípios da magia simpática e, sobre Eliade, consideraram importante sua análise sobre o tempo cíclico.

Já no $3^{\circ} \mathrm{TU}$, fizemos uma discussão sobre como a mitologia guarani, kaingang e laklãnõ-xokleng tem sido estudada na academia, a partir de uma pesquisa no banco de dados da Biblioteca Universitária. Também fizemos uma pesquisa no acervo de livros didáticos indígenas do NEPI (Núcleo de Estudos de Populações Indígenas) e no acervo virtual do LEMAD/USP ${ }^{4}$ (Laboratório de Ensino e Material Didático) e discutimos estratégias pedagógicas distintas para escolas indígenas, como jogos, videogame, vídeos e sites na internet.

Na disciplina Mitologia II, ofertada no semestre seguinte, propus que cada estudante escolhesse um tema relacionado à mitologia do seu povo, para se aprofundar. Esse seria o instrumento para podermos discutir os objetivos da disciplina, já apontados anteriormente: analisar as relações entre mito, rito, história, território, ambiente, atividades produtivas, grupos sociais; comparar as formas de transmissão desses conhecimentos e as formas de transmissão do conhecimento escolar; discutir sobre as possibilidades e desafios da utilização da mitologia na escola indígena: implicações da escrita dos mitos. A discussão

\footnotetext{
3 Os resultados desses trabalhos estão disponíveis na página do Curso LII: https://licenciaturaindigena.paginas.ufsc.br/files/2017/08/Guarani.vfinal.pdf; https://licenciaturaindigena.paginas.ufsc.br/files/2017/08/Kaingang.1.pdf; https://icenciaturaindigena.paginas.ufsc.br/files/2017/08/Xokleng.2.pdf.

4 Acessar: http://lemad.fflch.usp.br/painel.mdi.
} 
que segue está centrada nos trabalhos que idealizaram na primeira etapa e foram desenvolvendo ao longo do semestre.

A participação de Rosilene Pereira (Rosi Waikhon), então doutoranda no PPGAS/ UFSC, como estagiária docente da disciplina, foi muito enriquecedora, pois ela pode trazer elementos de sua pesquisa sobre infância e educação entre seu povo Piratapuia. A forma como ela relaciona a aprendizagem cotidiana das crianças ao acompanhar os pais em suas atividades nas roças, e o uso dos kirtí (narrativas curtas com fragmentos de mitos complexos) como estratégia didática tradicional (PEREIRA, 2013; 2019), ajudou muito a aproximar conhecimentos que eram tidos como de universos muito diferentes: agricultura, mitologia e escola.

O quadro a seguir foi extraído dos diários de aulas, apresentando os temas que estudantes de cada turma selecionaram para se aprofundar ao longo do semestre, os especialistas que pretendiam consultar ou os locais de pesquisa a serem visitados, além de algumas informações sobre o andamento da pesquisa. Alguns desses projetos foram desenvolvidos nos anos seguintes, durante as sucessivas disciplinas Projetos de Pesquisa e Ação e acabaram tornando-se os temas dos Trabalhos de Conclusão de Curso dos/as estudantes. Nesses casos, as referências são indicadas em notas.

Quadro 5 - Diário de aulas: Propostas de cada aluno/a para aprofundamento em temas da mitologia de seu povo, disciplina Mitologia II, em 2016

\begin{tabular}{|l|}
\hline \multicolumn{1}{|c|}{ TURMA GUARANI } \\
\hline Através da participação em atividades, proposta de observar o canto e dança, a educação corporal. \\
\hline Batismo guarani (Nhemongaraí). Vai falar com o txeramõi. ${ }^{5}$ \\
\hline Conhecimentos que são transmitidos na roça. Vai para a roça escutar as histórias. \\
\hline $\begin{array}{l}\text { Proposta de se reunir com os txeramõi para tentar conhecer as histórias que explicam porque } \\
\text { devemos respeitar as regras. }{ }^{6}\end{array}$ \\
\hline Grafismo tradicional. Vai conversar com o tio. $^{\text {Arte, grafismo dos balaios. }{ }^{7}}$ \\
\hline $\begin{array}{l}\text { Buscar recuperar as histórias que ouvia quando era pequeno e as formas de contar que produ- } \\
\text { ziam imagens como se fossem da televisão. Vai buscar os txeramõi. Vai falar com as crianças. }\end{array}$ \\
\hline $\begin{array}{l}\text { Proposta de conversar com anciões em relação aos plantios tradicionais. } \\
\text { Fizeram aula com as crianças e foram conversar com ancião e foram prá roça. }{ }^{8}\end{array}$ \\
\hline $\begin{array}{l}\text { Buscar ensinamentos sobre plantas, sementes, plumas que eram usadas em rituais, guerras, } \\
\text { festas, saudações e feitiços de cura. } \\
\text { Falou com várias pessoas. Aprendeu sobre feitiços. Ainda não fez a prática. Foram na Epagri } \\
\text { e pediram as plantas para plantarem na aldeia. }\end{array}$ \\
\hline Arte Xondaro. ${ }^{9}$ \\
\hline Levantamento sobre o tema do milho. Vai procurar o pessoal de Imaruí. \\
\hline
\end{tabular}

5 Silva, Darcy. Nhemongarai: Rituais de Batismo Mbya Guarani. TCC. LII/UFSC, 2020.

6 Antunes, Elisandro Karai. Nhandereko Ypy Kue. TCC. LII/UFSC, 2020.

7 Martins, Gennis Timóteo. Kunhangue arandu rekó, tá ánga re á egui nhembopara: sabedoria dos ciclos de vida das mulheres guarani em pinturas e palavras. TCC. LII/UFSC, 2020.

8 Sousa, Ismael. Nhamandu: Histórias e Narrativas Guarani. TCC. LII/UFSC, 2020.

9 Gonçalves, Leonardo da Silva. O Xondaro: aspectos da formação física, comportamental e espiritual do povo Guarani. TCC. LII/UFSC, 2020. 


\section{TURMA GUARANI}

Buscar a erva pi-pi, que não existe mais na sua aldeia. Trouxe seis mudas de Biguaçu. Vai entrevistar a avó, a mãe, o pessoal de lá. ${ }^{10}$

Decidiu pesquisar sobre plantas medicinais. Vai falar com Txedjari.

Vai buscar na memória as histórias que a avó lhe contava e buscar contar para as crianças da mesma forma. História da origem do fogo. Escreveu em guarani e corrigiu e traduziu para o português. Quer trabalhar na alfabetização. ${ }^{11}$

Sementes tradicionais de milho: vai procurar 3 tipos que não tem mais na sua aldeia Em janeiro e fevereiro vai no Rio Grande, Argentina e Paraguai.

\section{TURMA KAINGANG}

Pretende criar um calendário na sua escola para fazer eventos que tragam anciões, como a "noite cultural". Valorização do conhecimento das narrativas Kaingang. Ia entrevistar o avô, mas não conseguiu. Entrevistou a mãe. Agora pretende entrevistar o avô.

Através de atividades como a batida do cipó e a melagem, vai buscar os conhecimentos que envolvem e o desenvolvimento de um calendário.

Projeto em parceria com colegas da mesma aldeia. Dividiram o projeto em três.

A recuperação dos peixes vai demorar vários anos. Estão pensando em alternativas. Fazer açudes? Buscar parcerias com o Estado? Necessidade de repovoar os rios que têm na área.

Matemática Indígena Kaingang. Acontece espontaneamente sem perceber.

Tirar madeira prá fazer as casas. Grafismos. Medidas de roças.

Reprodução humana para a escolha do sexo dos bebês. Conhecimentos da esposa e sogra.

Participação do grupo de dança que envolve ensaios e atividades tradicionais. ${ }^{12}$

Projeto em parceria com colegas da mesma aldeia.

Vai fazer a parte da melagem. Vai conversar com o cunhado, que já tirou fotos.

Através do projeto "Saberes Indígenas na Escola", experiências com comidas típicas, histórias. Vai se restringir às comidas típicas. Vai procurar os professores que têm conhecimentos das comidas. Contrastar com as crianças que não conhecem mais.

Queria trabalhar através dos preparativos da "noite cultural" em sua escola.

Agora vai dar outra linha para a pesquisa, trabalhando com as crianças. Como as crianças aprendem. Diferenças entre coisas que os pais ou mães ensinam. Aprendizagem do artesanato. Que línguas falam.

Como os Kaingang veem a gravidez, pesquisa com a avó que foi parteira. ${ }^{13}$

Ouvindo os colegas, achou importante pensar num trabalho sobre falar a língua Kaingang.

Entender como houve esse processo de perda da língua. Preconceitos contra quem fala e quem não fala.

Pretende fazer na comunidade Pinhalzinho uma noite cultural como nas outras aldeias, com a participação dos anciões. Participa do grupo Gatogn (apresentação cultural).

10 Oliveira, Mariza. Ma' Ety Reguá Agricultura e Sabedoria Mbya Guarani. TCC. LII/UFSC, 2020.

11 Veríssimo, Silvana Minduá. Educação Tradicional e o Uso da Tecnologia na Infância Guarani Kyringue Onheovanga Ha' E Jurua Mba' E Oiporu Onhembo' Ea Py. TCC. LII/UFSC, 2020.

12 Fidélis, Jaciane Goj. Expressões corporais Kaingang como forma de transmissão de saberes na Terra Indígena Apucaraninha: o NDn Ga. TCC. LII/UFSC, 2020.

13 Amaral, Marcos. Fazer Criança: das Concepções aos Contextos de Vivências e Brincadeiras das Crianças Indígenas Kaingang. TCC. LII/UFSC, 2020. 
Mitologia se Ensina na Escola? Reflexões a partir do Curso de Licenciatura Intercultural Indígena da UFSC

\section{TURMA KAINGANG}

Quer fazer uma relação entre os mitos que os velhos contam e o que encontra na literatura (Meliá, Borba, Nimuendaju).

Comidas Kaingang, junto ao Projeto Ação Saberes Indígenas na Escola. Vai falar com o professor e com a mãe. ${ }^{14}$

Projeto em parceria com colegas da mesma aldeia.

Proposta de construir um calendário de pesca com os alunos. Projeto para repovoar os três rios.

TURMA XOKLENG

Através de conversas com pessoas mais velhas, vai buscar a memória dos batizados antigos.

Através de pessoas que sabem fazer, vai buscar aprender sobre o ritual de previsão ou profecia (kó plág) $)^{15}$

Contos do povo.

Atividades esportivas.

Acompanhar atividades de alguns anciões em busca de conhecimentos sobre um pássaro sagrado.

Acompanhar a avó que faz massagens em gestantes e se aprimorar nesses conhecimentos. ${ }^{16}$

Trabalhar junto com pastores Xokleng o desafio: como fazer para não deixar a cultura acabar e não deixar de ser evangélica? ${ }^{17}$

Vai buscar conhecimentos de ervas medicinais relacionados à saúde da mulher.

Vai acompanhar o pai em busca de conhecimentos sobre ervas medicinais e mel.

Cantigas indígenas.

Através da participação em projeto do COMIN, vai buscar registrar histórias e mitos que estão se perdendo.

Através da participação em projeto com a PREMAVE, vai trabalhar os nomes e utilidades de árvores nativas. ${ }^{18}$

Fonte: Elaborado pela autora deste artigo

Os temas selecionados por cada estudante e o fato de que muitos deles continuaram a ser desenvolvidos até a elaboração de Trabalhos de Conclusão de Curso demonstram a pertinência e a potência de tratar as temáticas do mito e da mitologia na formação em Licenciatura Intercultural Indígena. De fato, mais de um terço dos TCCs desenvolvidos pela turma foram semeados nesse momento. Por outro lado, as críticas dos/as estudantes foram contribuições fundamentais para que pudéssemos reconceitualizar nossas categorias de análise, observando como temos encapsulado os conceitos de mito e mitologia no campo da razão, do intelecto, do pensamento, da reflexão. Talvez, preocupados em demonstrar que os mitos têm "lógica", acabamos transfigurando-os em abstrações, desterritorializando-os ou dessensibilizando-os.

\footnotetext{
${ }_{14}$ Paula, Sandra de. Alimentação Tradicional Kaingang: Plantas que alimentam, ervas que curam. TCC. LII/UFSC, 2020.

15 Pripra, Acir Caile. Koplág: O Ritual de Previsão Xokleng/Laklãnõ. TCC. LII/UFSC, 2020.

16 Camlem, Elaine Kosiklã. Cândida Patté, parteira tradicional do Povo Xokleng Laklãnõ: retomada de práticas tradicionais e a saúde das mulheres. TCC. LII/UFSC, 2020.

17 Tschucambang, Josiane. Ouvir os velhos, aprender com eles: memórias, histórias e conhecimentos dos anciões da Terra Indígena Xokleng/Laklanõ. TCC. LII/UFSC, 2020.

18 Cuzugni, Vilma. Dança das Árvores e a Dança da Voz: Jeito de dar Nome as Crianças no Povo Xokleng/Laklãnõ. TCC. LII/UFSC, 2020
} 
Ao contrário disso, as escolhas dos/as estudantes abarcaram uma multiplicidade de temas envolvendo o território, a vida social, a corporalidade: buscaram saber das roças, do plantio e das qualidades terapêuticas de certas ervas; saber do mel e das técnicas de melagem; saber da saúde das mulheres, do parto e da gestação; saber das danças, dos grafismos; saber de técnicas de pesca e de receitas tradicionais; buscaram histórias e rituais que estavam sendo esquecidos. Tudo isso foi buscado não como um saber acadêmico abstrato, mas como experiências renovadas, atualizadas em atividades envolvendo as escolas das aldeias e seus anciãos/anciãs.

Por essas razões, ao rediscutir o currículo do Curso LII/UFSC para sua continuidade, o Grupo de Trabalho constituído para esse fim ${ }^{19}$, após 20 reuniões de trabalho e 17 visitas a Terras Indígenas, optou por alterar os nomes das disciplinas, de Mitologia Indígena I e II para Memória Viva I e II.

\section{Considerações Finais}

O artigo procurou descrever os desafios e as potencialidades do ensino de Antropologia, ou dos temas antropológicos clássicos do "mito" e da "mitologia", para cursos de formação de professoras indígenas na Educação Superior, nos moldes das Licenciaturas Interculturais. As experiências nas disciplinas Mitologia Kaingang em 2011 e Mitologia Indígena I e Mitologia Indígena II em 2016, com seus erros e acertos, permitem compreender que o diálogo intercultural que embasa o currículo do curso não é um dado pronto, mas uma postura a ser constantemente atualizada.

Essa experiência amplia o sentido do que apontava Paulo Freire (1992, p. 112, 113):

[...] ao ensinar, o professor ou a professora re-conhece o objeto já conhecido. Em outras palavras, refaz sua cognoscitividade na cognoscitividade dos educandos. Ensinar é assim a forma que toma o ato de conhecimento que $o$ (a) professor(a) necessariamente faz na busca de saber o que ensina para provocar nos alunos seu ato de conhecimento também.

Pois, nesse ato de re-conhecimento do mito e da mitologia, refeito por meio da cognoscitividade dos/as estudantes indígenas, o que se passou foi uma ampliação do seu sentido, uma transformação do objeto inicialmente conhecido como "mito" para seu "re-fazimento" a partir da cognoscitividade dos/as educandos/as, para usar os termos freireanos, em dimensões pouco exploradas pela tradição euro descendente.

Em artigo sobre a disciplina Infância Indígena ministrada para a primeira turma do mesmo curso (TASSINARI et al., 2019) chegamos a uma conclusão semelhante:

As pesquisas realizadas pelos acadêmicos possibilitaram questionar e redimensionar os limites de um certo modo de conceitualizar a infância. Indicaram a necessidade de promovermos um deslocamento e extensão dos sentidos que temos dado à infância, conforme Strathern (2006) analisa em relação ao gênero. "O que está em jogo, nesse caso, são maneiras de criar as condições para novos pensamentos". (TASSINARI et al., 2019, p. 50)

\footnotetext{
19 Grupo de Trabalho instituído na UFSC através da Portaria n. 530/2019/GR, de 14 de março de 2019, e da Portaria n. 1.368/2019/GR, de 26 de junho de 2019.
} 
Percebemos que não bastava questionar a universalidade da infância e buscar as suas definições próprias, enquanto não reconhecêssemos que as metáforas que estávamos usando precisavam passar por um deslocamento de sentido. Se as noções de pureza, ingenuidade e fantasia já tinham sido anteriormente criticadas como metáforas universais para definir a infância (ARIÈS, 1981), os acadêmicos indígenas nos levaram mais além, deslocando as próprias noções de fase do ciclo de vida, de desenvolvimento, de oposição à vida adulta. (TASSINARI et al., 2019, p. 420)

Consideramos que esse esforço realizado na disciplina Infância Indígena gerou uma maior atenção às formas próprias de conceituar a infância e à necessidade de promover seu reconhecimento ou inclusão no cotidiano escolar. Possibilitou também, para os acadêmicos indígenas, reconhecer as formas ocidentais de conceituar infância que embasam a educação escolar, de forma a poder contrastá-las com as suas. (TASSINARI et al., 2019, p. 421)

Assim, no presente artigo, procurei analisar os desafios do ensino de Antropologia para um público que sempre ensinou os/as antropólogos/as sobre mitos e mitologia, mesmo sem conceitualizar seus conhecimentos nesses termos. Busquei descrever com sinceridade os erros e acertos desse percurso, entendendo que as minhas insistências em certos objetivos ou em assumir certas metáforas para categorizar o mito e a mitologia dizem respeito a modelos acadêmicos cristalizados em nossa disciplina e que merecem ser transformados, mesmo que isso não seja tarefa simples. Percebemos que não basta refletir sobre a importância ou adequação de abordar mitos e mitologia nas escolas indígenas. De fato, se quisermos nos engajar num diálogo intercultural genuíno, seja com finalidades pedagógicas ou antropológicas, precisamos reconhecer os limites da nossa linguagem, permitir deslocamentos de sentidos para reconceitualizar essas categorias a partir da cognoscitividade dos/as estudantes indígenas.

\section{Referências}

BRASIL. Referenciais Curriculares Nacionais para Escolas Indígenas (RCNEI). Brasília, DF: MEC, 1997.

BRASIL. Guia do Formador: Programa Parâmetros em Ação de Educação Escolar Indígena. Brasília, DF: MEC, 2002. 240p.

CRÉPEAU, Robert. Mito e Ritual entre os Índios Kaingang do Brasil Meridional. Horizontes Antropológicos, Porto Alegre, ano 3, n. 6, p. 173-186, out. 1997.

FONSECA, Claudia. Fofocas e Violência. In: FONSECA, Claudia. Fofoca, Família e Honra. Porto Alegre: Editora UFRGS, 2000. p. 13-52.

FREIRE, Paulo. Pedagogia do Oprimido. Rio de Janeiro: Paz e Terra, 1987 [1970].

FREIRE, Paulo. Pedagogia da Esperança. Rio de Janeiro: Paz e Terra, 2020 [1992].

GRANDO, Beleni. Jogos e Culturas Indígenas: possibilidades para a educação intercultural na escola. Cuiabá: EdUFMT, 2010.

LOPES DA SILVA, Aracy. Mitos e Cosmologias Indígenas no Brasil: breve introdução. In: GRUPIONI, Luís Donisete. (org.) Índios no Brasil. São Paulo: Secretaria Municipal de Cultura, 1992. p. 75-82. 
LOPES DA SILVA, Aracy. Mito, Razão, História e Sociedade: inter-relações nos universos sócio-culturais indígenas. In: LOPES DA SILVA, A.; GRUPIONI, L. D. B. (org.). A temática indígena na escola. Brasília, DF: MEC/MARI/UNESCO, 1995. p. 317-339.

MELO, Clarissa R. de. Da Universidade à Casa de Rezas Guarani e Vice-Versa: reflexões sobre a presença indígena no Ensino Superior a partir da experiência dos Guarani na Licenciatura Intercultural Indígena do Sul da Mata Atlântica. 2014. 405 p. Tese (Doutorado em Antropologia Social) - Universidade Federal de Santa Catarina, Florianópolis, 2014.

OLIVEIRA, Melissa. Kyringué i kuery guarani: Infância, educação e religião entre os Guarani de M’Biguaçu, SC. 2004. 112 f. Dissertação (Mestrado em Antropologia Social) Universidade Federal de Santa Catarina, Florianópolis, 2004.

PEREIRA, Rosilene Fonseca. Criando gente no alto Rio Negro: um olhar waíkhana. 2013. 116f. Dissertação (Mestrado em Antropologia Social) - Universidade Federal do Amazonas, Manaus, 2013.

PEREIRA, Rosilene Fonseca. Roças: espaços de construção da ciência indígena na região do alto Rio Negro, conhecimentos que não são à toa. In: TASSINARI, A.; MONTARDO, D. L.; VIEIRA, J. G. (org.). Antropologia e Educação: refletindo sobre processos educativos em contextos escolares, não escolares e de políticas públicas. Tubarão; Manaus; Natal: Copiart; Edua: Edufrn, 2019. p. 33-48.

PEREIRA, Rosilene Fonseca. Cuidados na criação de gente: habilidades e saberes importantes para viver no Alto Rio Negro. 2021. 201 p. Tese (Doutorado em Antropologia Social) - Universidade Federal de Santa Catarina, Florianópolis, 2021.

PPP - PROJETO POLÍTICO PEDAGÓGICO. Curso Licenciatura Intercultural Indígena do Sul da Mata Atlântica. Florianópolis: UFSC, 2015.

STRATHERN, Marilyn. O gênero da Dádiva: problemas com as Mulheres e Problemas com a Sociedade na Melanésia. Campinas: Editora da Unicamp, 2006.

TASSINARI, Antonella. Escola indígena: novos horizontes teóricos, novas fronteiras de educação. In: LOPES DA SILVA, Aracy; FERREIRA, Mariana (Org.). Antropologia, história e educação: a questão indígena e a escola. São Paulo: Global, 2001, p. 44-70.

TASSINARI, Antonella; JESUS, Suzana; Melo, Clarissa. Infância indígena no Sul do Brasil: considerações a partir de uma disciplina de Licenciatura Indígena. R@U, São Carlos, n.11, vol.1, p. 401-423, jan.-jun. 2019.

VANSINA, Jan. A Tradição Oral e sua Metodologia. In: KI-ZERBO, Joseph. (org.). História Geral da África. Brasília, DF: Unesco, 2010. v. 1. p. 139-166.

VERnANT, Jean-Pierre. As Origens do Pensamento Grego. Rio de Janeiro: Difel, 2002.

VIERTLER, Renate. Adaptação de mitos indígenas na literatura infantil brasileira. Revista de Antropologia, [s.l.], v. 22, 11 p. 1979.

\section{Antonella Tassinari}

Antropóloga, com graduação em Ciências Sociais (1990) e doutorado em Ciência Social (Antropologia) na Universidade de São Paulo (1998). Realizou estágio pós-doutoral no EREA (Centre Enseignement et Recherche en Ethnologie Amérindienne) em convênio com a Université de Paris X Nanterre (2005) e no Departamento de Antropologia da Universidade de Montréal, Canadá (2014/2015). É Professora Titular da Universidade Federal de Santa Catarina, vinculada ao Departamento de Antropologia, onde desenvolve projetos de pesquisa e extensão no Núcleo de Estudos de Populações Indígenas (NEPI). Atualmente coordena o Curso e Graduação em Antropologia na UFSC. É membro do Conselho Científico da Associação Brasileira de Antropologia. Tem experiência na área de Antropologia, com ênfase em Etnologia Indígena, Antropologia da Educação e Antropologia da Criança, atuando principalmente nos 
Mitologia se Ensina na Escola? Reflexões a partir do Curso de Licenciatura Intercultural Indígena da UFSC

seguintes temas: povos indígenas, infância e educação indígenas, identidade étnica, diversidade cultural e educação escolar, história e ensino de Antropologia.

Endereço profissional: Departamento de Antropologia. Campus Universitário Reitor João David Ferreira Lima, Trindade, Florianópolis, SC. CEP 88040-900.

E-mail: antonella.tassinari@ufsc.br

ORCID: https://orcid.org/0000-0002-8649-7593

\section{Como referenciar este artigo:}

TASSINARI, Antonella. Mitologia se Ensina na Escola? Reflexões a partir do Curso de Licenciatura Intercultural Indígena da UFSC. Ilha - Revista de Antropologia, Florianópolis, v. 24, n. 1, e81138, p. 13-32, janeiro de 2022. 